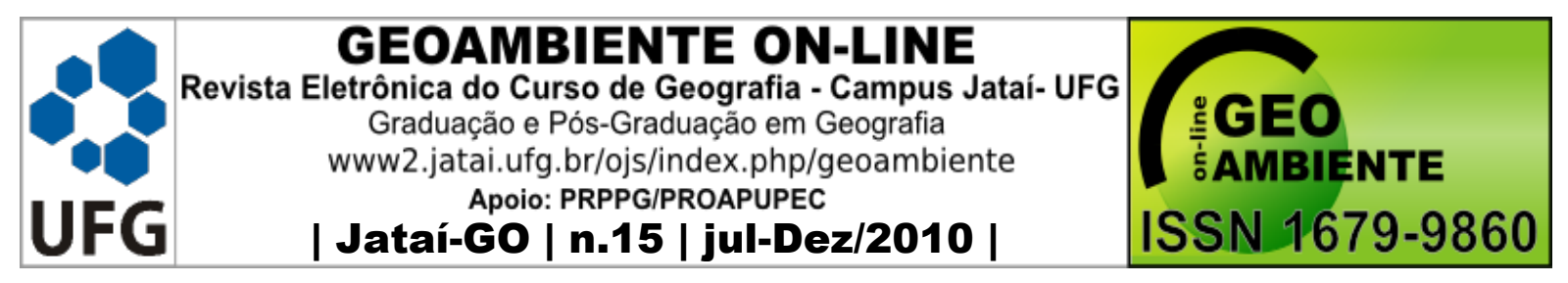

\title{
TOMOGRAFIA ELÉTRICA-2D APLICADA NO LIXÃO DO MUNICÍPIO DE SAUDADE DO IGUAÇU-PR
}

Valter Antonio Becegato ${ }^{1}$, Rodoilton Stefanato $^{2}$, Francisco José Fonseca Ferreira ${ }^{2}$, João Batista Pereira $\mathrm{Cabral}^{3}$, Vitor Rodolfo Becegato ${ }^{1}$

(1 - Pesquisador, Universidade do Estado de Santa Catarina, Departamento de Engenharia Ambiental; becegato@cav.udesc.br, vitortiburon_92@yahoo.com.br; 2 - pesquisador, Universidade Federal do Paraná - LPGA; rodoilton@ufpr.br; francisco.ferreira@ufpr.br; 3 Pesquisador, Universidade Federal de Goiás - Campus Jataí - GO; Jbcabral2000@yahoo.com.br)

\section{Resumo}

A presente pesquisa é oriunda de trabalhos geofísicos realizados para a Prefeitura Municipal de Saudade do Iguaçu no estado do Paraná-Brasil, objetivando obter a possível pluma de contaminação do depósito de lixo desativado do referido município. Tais ensaios envolveram a aplicação do método geofísico da eletrorresistividade através do arranjo dipolo-dipolo. A área situa-se na bacia do Paraná, inserida na formação Serra Geral, constituídas por rochas magmáticas.

Palavras-chaves: Resistividade, Lixo, Contaminação

\section{Abstract \\ GEOPHYSICAL INVESTIGATIONS APPLIED IN THE GARBAGE DEPOSIT OF THE CITY OF SAUDADE DO IGUAÇU-BRAZIL}

The present research derives from geophysical works carried through for the City of Saudade do Iguaçu in the state of Paraná-Brazil, objectifying to obtain the possible contamination's plume of the disactivated dump deposit of the related city. Such assays had involved the application of the geophysical method of the resistivity through the dipole-dipole array. The area is located in the Bacia do Paraná inserted in the Serra Geral's formation, constituted of magmatic rocks.

Keywords: Resistivity, Dump, Contamination

\footnotetext{
Artigo recebido para publicação em 08 de agosto de 2010

Artigo aprovado para publicação em 23 de Novembro de 2010
} 


\section{Resumen \\ TOMOGRAFIA ELÉCTRICA-2D APLICADA EN EL VERTEDERO DEL MUNICÍPIO DE SAUDADE DO IGUAÇU-BRASIL}

La presente pesquisa deriva de trabajos geofísicos realizados para la Prefectura Municipal de Saudade do Iguaçu, en el estado de Paraná-Brasil, objectivando obtener el posible penacho de contaminación del vertedero desactivado del referido município. Estos ensayos incluían la aplicación del método de la resistividad geofísica de la eletroresistividad a través de la matriz dipolo-dipolo. El área está ubicada em la cuenca del Paraná, inserida en la formación Serra Geral, formada por rocas magmáticas.

\section{Palabras clave: Resistividad, Basura, Contaminación}

\section{1 - Introdução}

Um dos grandes desafios enfrentados pelos municípios brasileiros é a destinação do lixo produzido principalmente nas áreas urbanas, face ao aumento do consumo que vem ocorrendo paulatinamente. Neste sentido, os resíduos gerados e depositados no meio ambiente, seguramente irão gerar alguma forma de agressão e impactar o ambiente.

A problemática do lixo no meio urbano abrange alguns aspectos relacionados à sua origem e produção, assim como o conceito de inesgotabilidade e os reflexos de comprometimento do meio ambiente, principalmente a poluição do solo, ar e dos recursos hídricos.

A prática mais habitual e conveniente é o uso de buracos escavados a céu aberto “lixões” em terrenos próximos as áreas urbanas, onde é depositado todo tipo de material descartável e de fácil decomposição. A poluição das águas superficiais e subterrâneas pelo lixo é propiciada por uma série de fenômenos naturais como a lixiviação, percolação, arrastamento, solução entre outros (Lima, 2004).

As águas das chuvas percolando através da massa de resíduos transportam um líquido de cor negra, denominado de chorume ou sumeiro, oriundo dos materiais orgânicos em decomposição. Tal líquido provém de três fontes principais: a) umidade natural do lixo, que se agrava sensivelmente nos períodos de chuva; b) água de constituição dos vários materiais que sobra durante a decomposição; c) líquido proveniente da dissolução de matéria orgânica pelas enzimas expelidas por bactérias. 
De forma geral as rochas e o subsolo são maus condutores de corrente elétrica, cujas resistividades seriam altas se não fossem a presença de poros e fraturas preenchidos por líquidos (Telford et al. 1990). Líquidos como o chorume de cor negra liberado pela decomposição de lixo, tem em sua constituição sais dissolvidos, apresentando baixa resistividade, facilitando a passagem da corrente elétrica.

Uma das formas mais eficientes e econômicas de se verificar a existência de áreas contaminadas ocasionadas pela decomposição do lixo, é a utilização de métodos geofísicos que são técnicas indiretas de investigação das estruturas de sub-superfície através da aquisição e interpretação de dados instrumentais, caracterizando-se, portanto, como métodos não invasivos ou não destrutivos.

\section{Material e Métodos}

\subsection{Características d área}

A área de estudos (Figura 1) está inserida entre as coordenadas geográficas $25^{\circ}$ 41'11,08 S e 52³8’01.8”' W município de Saudade do Iguaçu-PR.

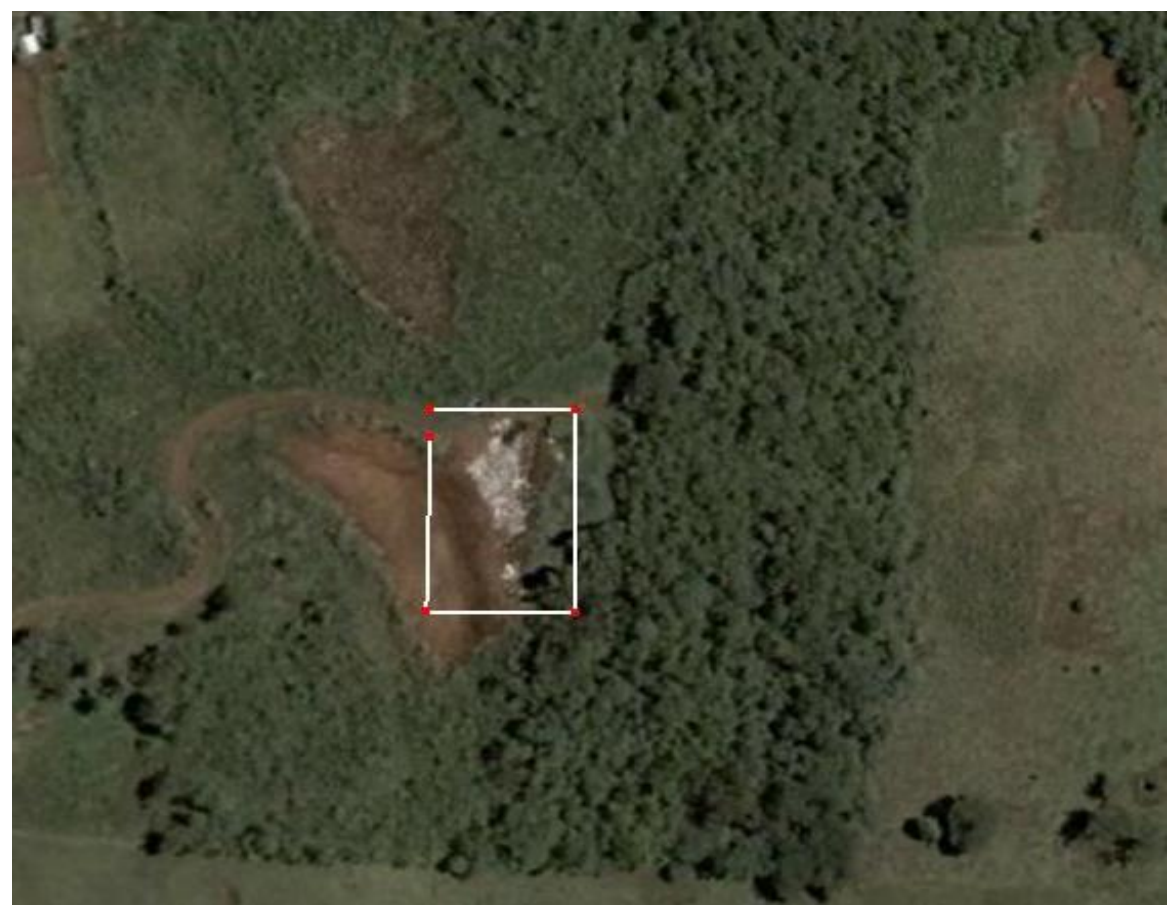

Figura 1. Polígono delimitando a área de estudos. Fonte: Google Earth, 2007.

O depósito de lixo "lixão" (Figuras 2 e 3) com dimensões de 100 x 100 metros inserida na área rural, que serve como depósito de lixo, estava recebendo até 2007 um volume diário de aproximadamente 1 tonelada de resíduos. 
Tal prática é corrente na grande maioria dos municípios brasileiros pela falta de aterros sanitários, cujo objetivo é recolher o líquido (chorume) trata-lo e devolve-lo ao meio ambiente, em níveis paramétricos que atendam as resoluções ambientais brasileiras em nível federal e estadual.

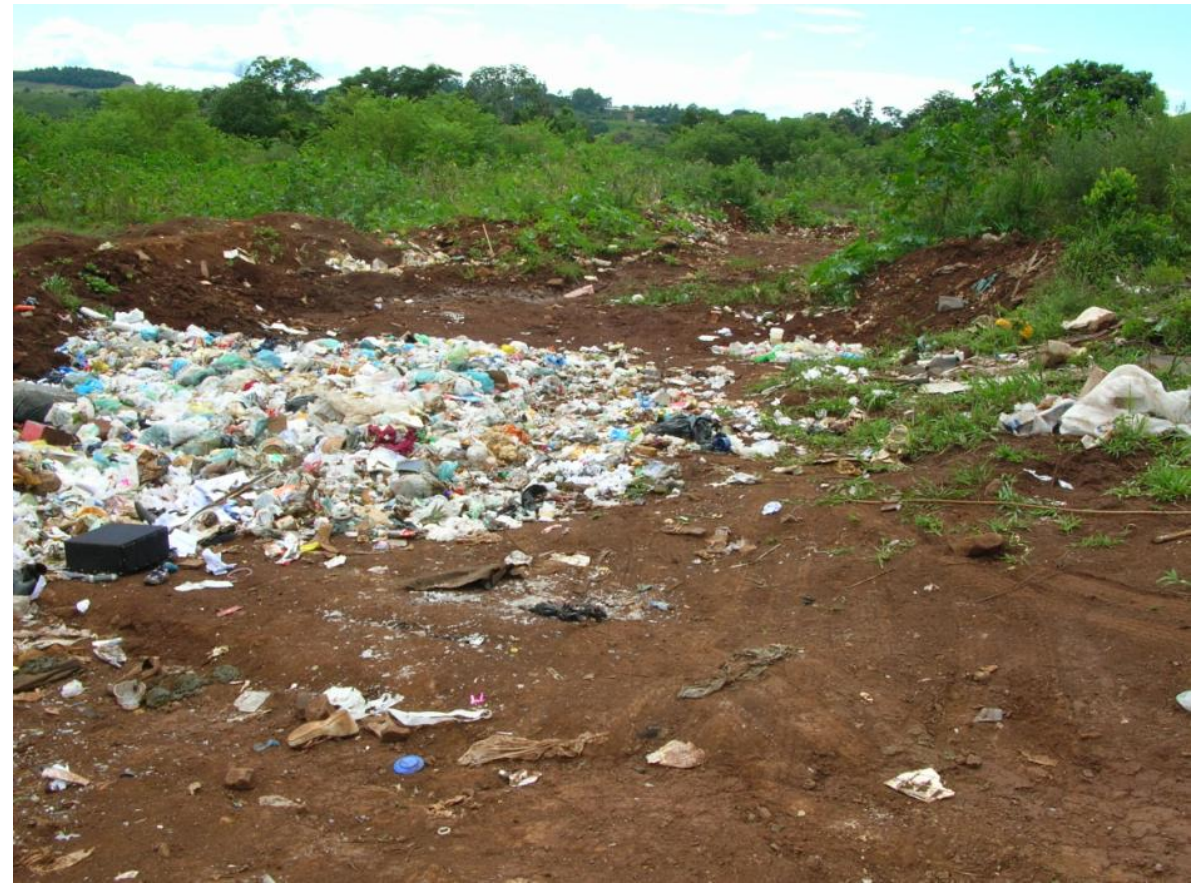

Figura 2. Vista parcial do lixão

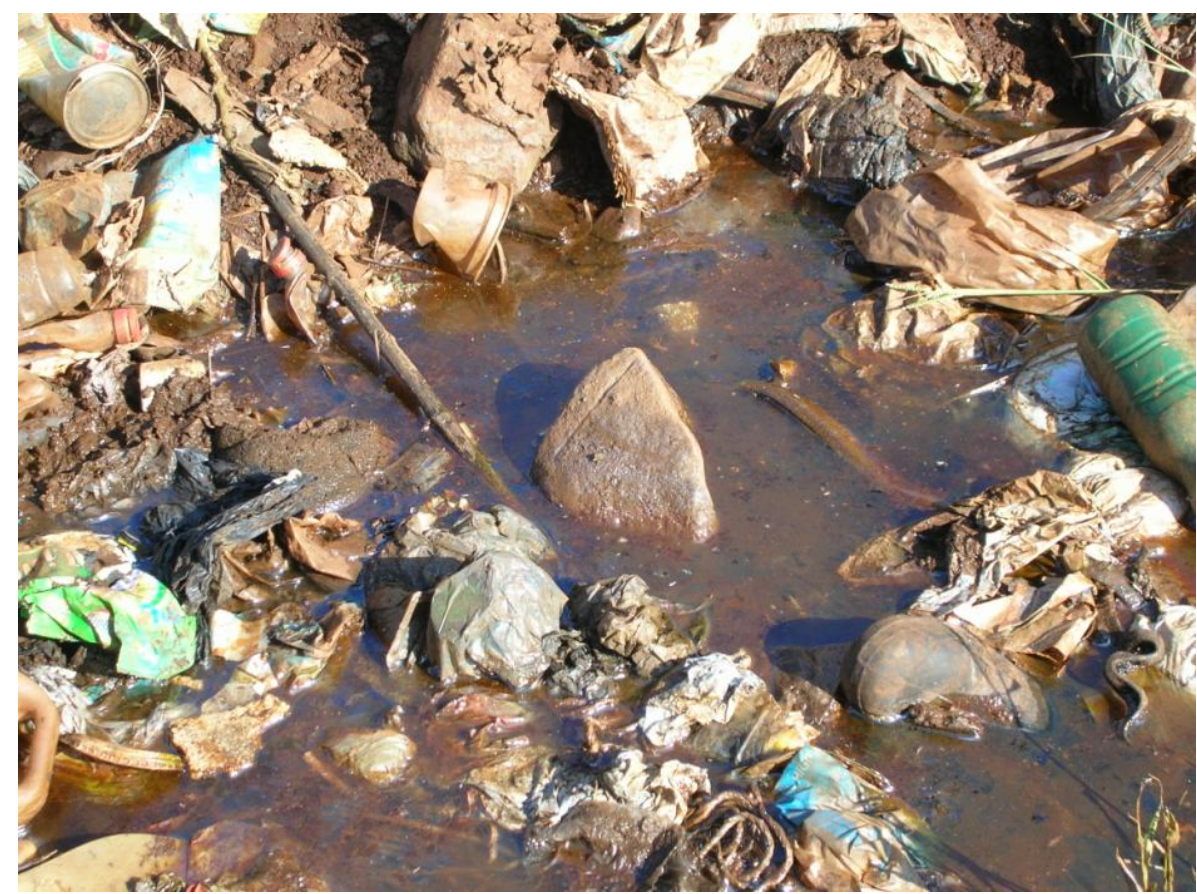

Figura 3. Vista parcial do lixão com exposição do chorume 


\subsection{Diagnóstico do Meio Físico}

\subsubsection{Geologia Regional e Local}

Durante o período Juro-Cretáceo (145 milhões de anos), uma intensa atividade vulcânica afetou toda a região Sul do Brasil, correndo uma série de extravasamento de lavas, através de zonas de fraqueza.

O magma formado no interior da Terra, aproveitando as zonas de fraqueza, foi conduzido à superfície de forma intermitente e sucessiva, dando origem aos vários derrames basálticos, que constituem hoje a formação geológica Serra Geral (Figura 4), do grupo São Bento.

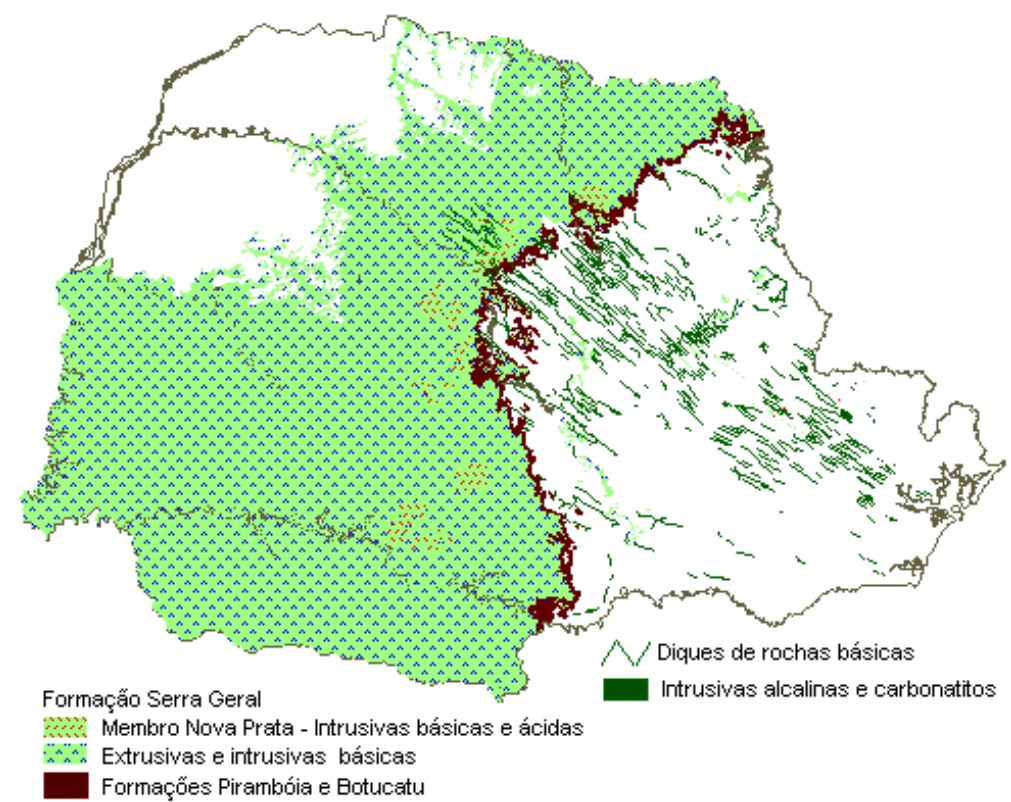

Figura 4. Distribuição espacial da formação Serra Geral no estado do Paraná. Fonte: Paraná, (2000).

Após o vulcanismo, toda a região esteve sujeita há movimentos verticais da crosta terrestre, que provocaram o soerguimento do embasamento rochoso, dando origem a Serra do Mar. Essa movimentação ocorreu predominantemente ao longo das estruturas pré-existentes, causando a inclinação dos blocos rochosos da borda da bacia para oeste, influindo na configuração dos cursos das águas. Os rios passaram a esculpir uma nova rede de drenagem que originou a atual bacia hidrográfica do rio Paraná, onde se inclui o rio Iguaçu (Piccirilo \& Melfi, 1998).

O vulcanismo fissural da Bacia do Paraná representa uma das maiores manifestações de vulcanismo continental do globo. Esse vulcanismo está representado na região por espessos e extensos derrames de lavas, bem como por diques e soleiras, com pequenos e 
eventuais corpos de rochas sedimentares associados. Tal conjunto de litologias constitui a formação Serra Geral, dividida em duas porções: a seqüência básica e a seqüência ácida (Marques, 1988).

A região sudoeste do Paraná está inserida na formação Serra Geral e especificamente a área de estudos localiza-se em unidade litoestratigráfica (Figura 5) com área de cobertura no Terceiro Planalto ou Planalto de Trapp do Paraná.

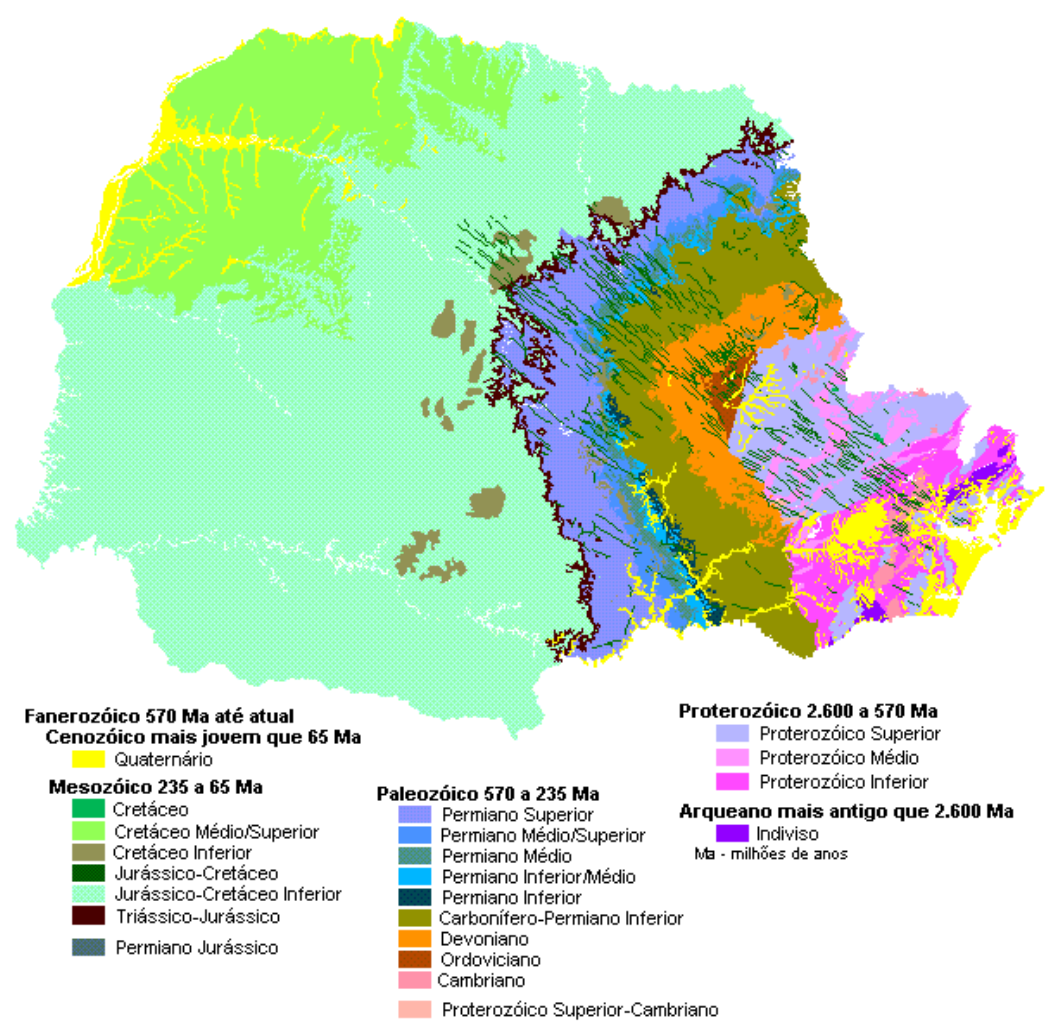

Figura 5. Distribuição espacial da litoestratigrafia do estado do Paraná.

Á área de estudo apresenta superfície fortemente inclinada (Figura 6) para o leste, cuja morfologia está influenciada pela estrutura tabular dos derrames de basalto. O relevo de toda a Região Sul do Brasil apresenta grande variedade de aspectos geomorfológicos decorrentes da superimposição de sistemas climáticos, das condicionantes de natureza litológica e estrutural variadas, e de fatores de ordem biológica, através da ação humana que, junto com os demais fatores interatuantes, são os responsáveis pela mudança energética do ambiente, rompendo o equilíbrio morfodinâmico. A interação dos dois primeiros fatores, predominantemente a presença de diversas superfícies aplanadas, sedimentadas e de acumulação, apresenta diferentes níveis altimétricos, constituindo diversos compartimentos geomorfológicos. 


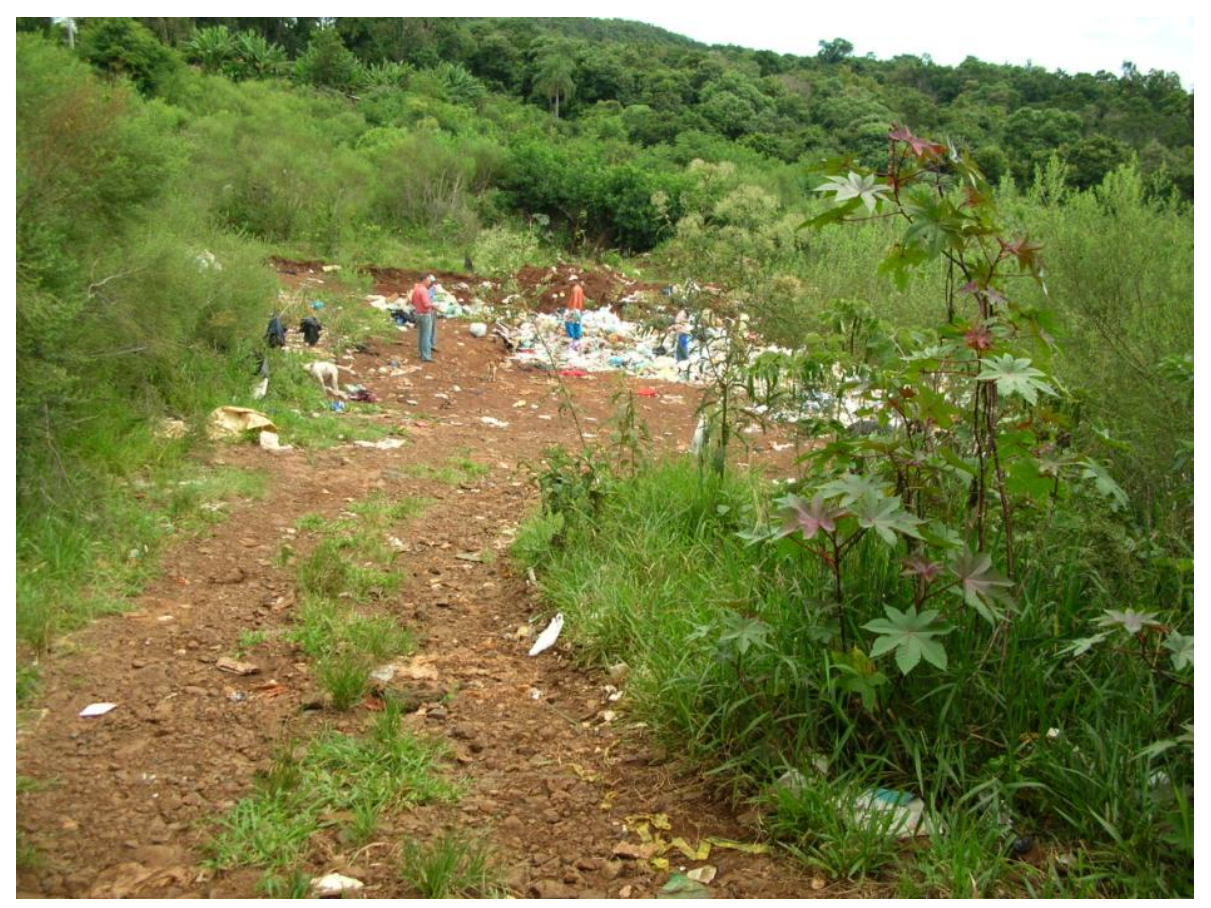

Figura 6. Aspecto do relevo da área de estudos.

\subsubsection{Geomorfologia}

Á área de estudo apresenta superfície fortemente inclinada (Figura 6) para o leste, cuja morfologia está influenciada pela estrutura tabular dos derrames de basalto. O relevo de toda a Região Sul do Brasil apresenta grande variedade de aspectos geomorfológicos decorrentes da superimposição de sistemas climáticos, das condicionantes de natureza litológica e estrutural variadas, e de fatores de ordem biológica, através da ação humana que, junto com os demais fatores interatuantes, são os responsáveis pela mudança energética do ambiente, rompendo o equilíbrio morfodinâmico. A interação dos dois primeiros fatores, predominantemente a presença de diversas superfícies aplanadas, sedimentadas e de acumulação, apresenta diferentes níveis altimétricos, constituindo diversos compartimentos geomorfológicos.

O relevo do Estado do Paraná é caracterizado pelo predomínio de um conjunto de relevos de planaltos, que se elevam em altitudes acima de $1.000 \mathrm{~m}$ sobre o nível do mar, descendo a altitudes inferiores a 300 m, na direção oeste. De leste para oeste, após a Planície Litorânea e a Serra do Mar, o relevo paranaense apresenta uma sucessão de três planaltos separados por duas escarpas (Maack, 1981).

Além desse comportamento generalizado da topografia é importante observar a variação de altimetria em função do aprofundamento da drenagem dos rios principais, como é o caso do rio Iguaçu, que apresenta seus vales encaixados em vários trechos com desníveis, entre as partes interfluviais e o fundo de vale, acentuados em função da potência e do 
gradiente do rio. Os desníveis existentes nos contatos entre as áreas conservadas e as áreas dissecadas são marcadas, em muitos setores da unidade, por uma forte ruptura de declive em degraus, formando patamares.

\subsection{Métodos Geofísicos}

Devido a grande heterogeneidade do meio geológico, é natural que cada tipo litológico apresente uma resposta diferente em relação ao parâmetro físico da resistividade elétrica. De outra maneira, este parâmetro pode refletir diferentes formas de ocorrência de um mesmo material geológico, servindo para caracterizar seus estados, em termos de alteração, fraturamento, saturação, conteúdo mineral, etc.

A resistividade elétrica de uma substância pode ser definida como a resistência à passagem de corrente (Koefoed, 1979).

Uma rocha condutora de corrente elétrica pode ser considerada como sendo um agregado com estrutura de minerais sólidos, líquidos e gases, na qual sua resistividade é influenciada pelos seguintes fatores (Braga, 2002):

Resistividade dos minerais que formam a parte sólida da rocha;

Resistividade dos líquidos e gases que preenchem seus poros;

Umidade da rocha;

Porosidade da rocha;

Textura da rocha e a forma e distribuição de seus poros; e

Processos que ocorrem no contato dos líquidos contidos nos poros e na estrutura mineral.

\section{Arranjo Dipolo-Dipolo (Imageamento Elétrico 2-D)}

Definiu-se quatro linhas sobre a área do lixão, objetivando-se a aquisição dos dados geoelétricos, cujas características das mesmas encontra-se na (Tabela 1). Na Figura 7 podemse visualizar os procedimentos da disposição dos arranjos das linhas para aquisição dos dados geoelétricos.

Tabela 1 - Linhas do levantamento dipolo-dipolo realizado na área do lixão.

\begin{tabular}{|l|l|l|}
\hline Linhas dipolo-dipolo & Comprimento $(\mathrm{m})$ & Sentido \\
\hline L1 & 110 & W - E \\
\hline L2 & 120 & W - E \\
\hline L3 & 100 & S - N \\
\hline
\end{tabular}




\begin{tabular}{|l|l|l|}
\hline L4 & 100 & $\mathrm{~S}-\mathrm{N}$ \\
\hline
\end{tabular}

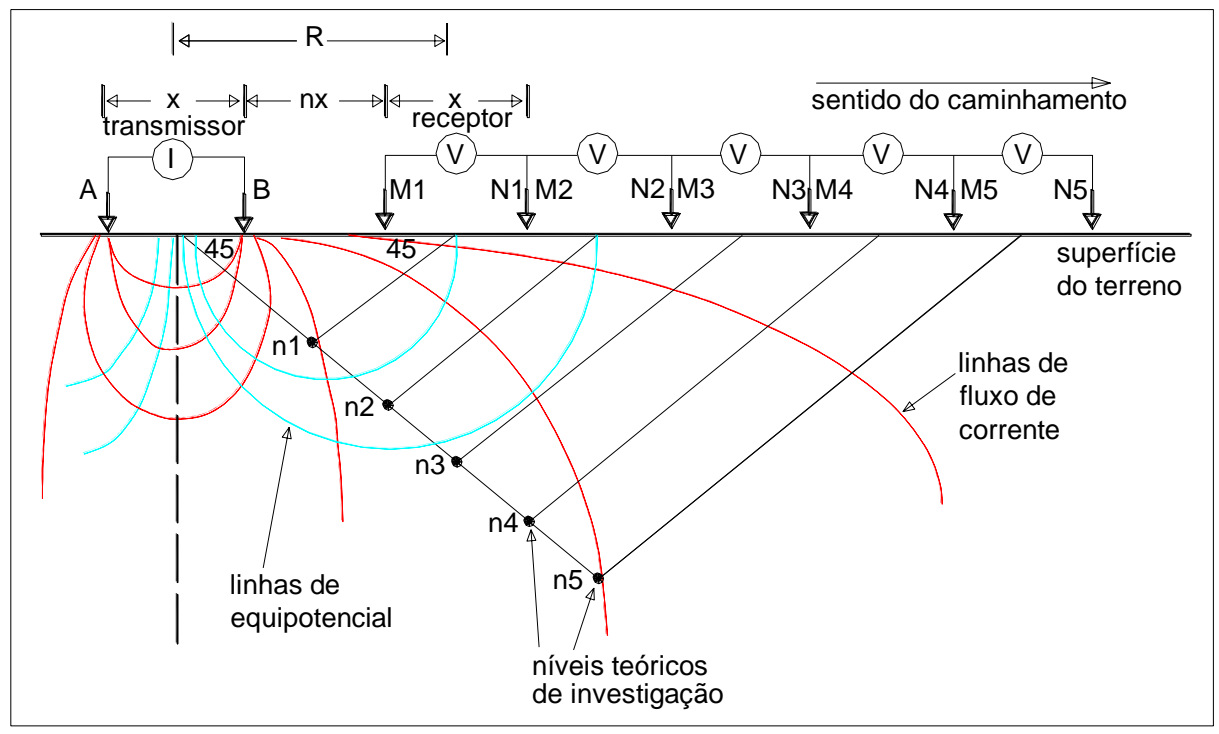

Figura 7. Procedimento do caminhamento elétrico através do arranjo dipolo-dipolo indicando os eletrodos de corrente (Transmissor AB), de potencial (Receptor MN), linhas de equipotencial, de corrente e níveis teóricos de investigação.

Na prática dos levantamentos de imageamento elétrico 2-D, denomina-se geralmente a fonte de corrente como circuito transmissor, ou simplesmente transmissor, e os circuitos relacionados com os eletrodos de potencial como receptor. $\mathrm{O}$ arranjo eletródico normalmente utilizado neste tipo de levantamento é o dipolo-dipolo, onde a separação entre os eletrodos de corrente $(\mathrm{AB})$ é a mesma dos eletrodos de potencial $(\mathrm{MN})$, e a distância entre seus pontos médios é um múltiplo deste espaçamento.

Os caminhamentos elétricos são usualmente feitos ao longo de linhas ou perfis. O procedimento mais comum é posicionar os eletrodos de corrente $(\mathbf{A B})$ no início da linha. As leituras são feitas através de pares sucessivos de eletrodos de potencial (MN), igualmente espaçados. O transmissor (AB) é então deslocado para a próxima posição, na mesma linha, e o procedimento é então repetido; cujo procedimento é ilustrado na Figura 8.

A Figura 8 mostra os pontos de leitura (interseções), a partir de posições sucessivas do transmissor. Para cada posição do transmissor, o procedimento ilustrado (b) é repetido. Esta forma de apresentação dos dados, denominada pseudoseção, permite que os valores de resistividade sejam contornados, como esquematizado em (c), gerando uma imagem da posição relativa das fontes. Entretanto, como referido, tais contornos não refletem o posicionamento real das fontes, mas uma aproximação de onde uma determinada fonte pode 
estar situada e se a mesma é relativamente rasa ou profunda. Neste tipo de arranjo o fator geométrico $\boldsymbol{K}$ é obtido pela equação:

$$
K=\pi a Q(Q+1)(Q+2)(3) \text {, onde a= espaçamento } \mathrm{AB}=\mathrm{MN}
$$

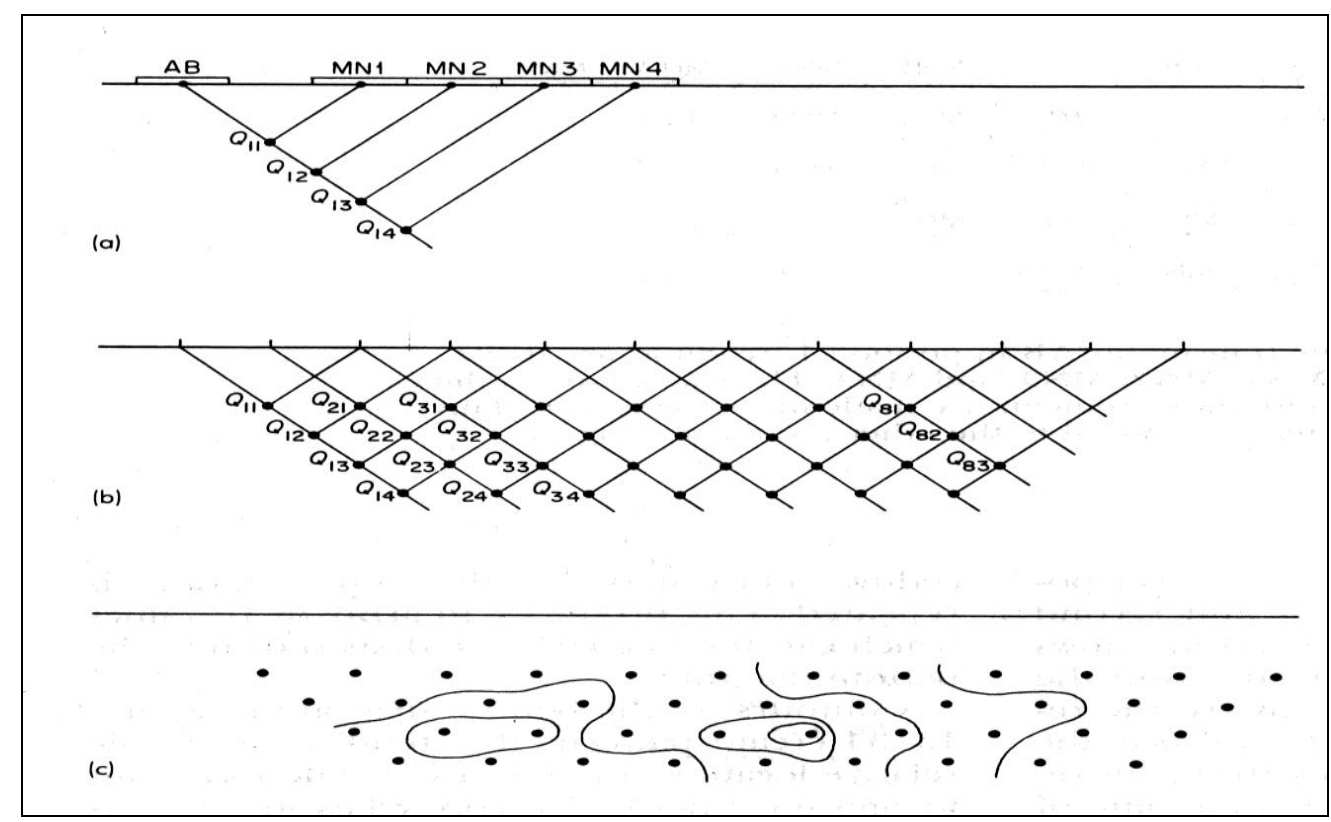

Figura 8. Representação de uma pseudoseção de medidas de um caminhamento elétrico.

Ao utilizar um mesmo arranjo de eletrodos para efetuar medições sobre um meio heterogêneo, a diferença de potencial $(\Delta \mathbf{V})$ será diferente da registrada sobre um meio homogêneo, pois o campo elétrico deverá sofrer modificações em função desta heterogeneidade.

Como na prática o subsolo não pode ser considerado um meio homogêneo, o valor medido de resistividade não pode ser atribuído a apenas um ponto no subsolo, e sim uma média ponderada de todas as resistividades envolvidas dentro do semi-espaço amostrado, pois refletem a resposta de um volume de solo ou rocha por onde a corrente circula. Em função desta constatação é utilizado o termo resistividade aparente $\left(\rho_{a}\right)$ que é dado pela expressão (1), a qual não obedece mais a Lei de Ohm. Em outras palavras, a resistividade aparente $\left(\rho_{a}\right)$ não é um parâmetro físico do meio, mas um efeito integrado sobre um segmento do semiespaço, para a qual contribuem os valores da resistividade em cada ponto, a geometria elétrica do terreno e a disposição geométrica dos eletrodos.

$$
\rho_{a}=K * \Delta V / I(1)
$$


O fator $\boldsymbol{K}$ que multiplica $\Delta \mathbf{V} / \mathbf{I}$ é puramente geométrico e depende apenas da disposição dos eletrodos A, B, M e N. Como existem várias formas de arranjar os eletrodos no terreno, o fator $\boldsymbol{K}$ poderá ser calculado através de expressões específicas ou de acordo com a equação geral:

$$
K=2 \pi(1 /|A M|-1 /|B M|-1 /|A N|+1 /|B N|)^{-1}(2)
$$

\section{Aquisição e processamento dos dados geofísicos}

Os dados de resistividade obtidos na área do lixo desativado foram adquiridos através do arranjo dipolo-dipolo, também conhecido como caminhamento elétrico, imageamento elétrico 2-D ou tomografia elétrica 2-D.

Os equipamentos utilizados são compostos por dois módulos, um de transmissão de corrente alimentado por baterias (VT250) e outro constituído por um receptor designado eletrorresistivímetro VR250 (Figura 9), ambos da marca AC ABEM. O conjunto transmissor é conectado aos eletrodos de corrente $\mathbf{A}$ e $\mathbf{B}$, enquanto o sistema de recepção é acoplado a outros dois eletrodos chamados de potencial $\mathbf{M}$ e N. O processamento dos dados geofísicos foi realizado através do software Oasis Montaj $^{T M}$ e Zonge 2-D Inversion for Interactiv ${ }^{T M} I P$ da Geosoft/Interpex.

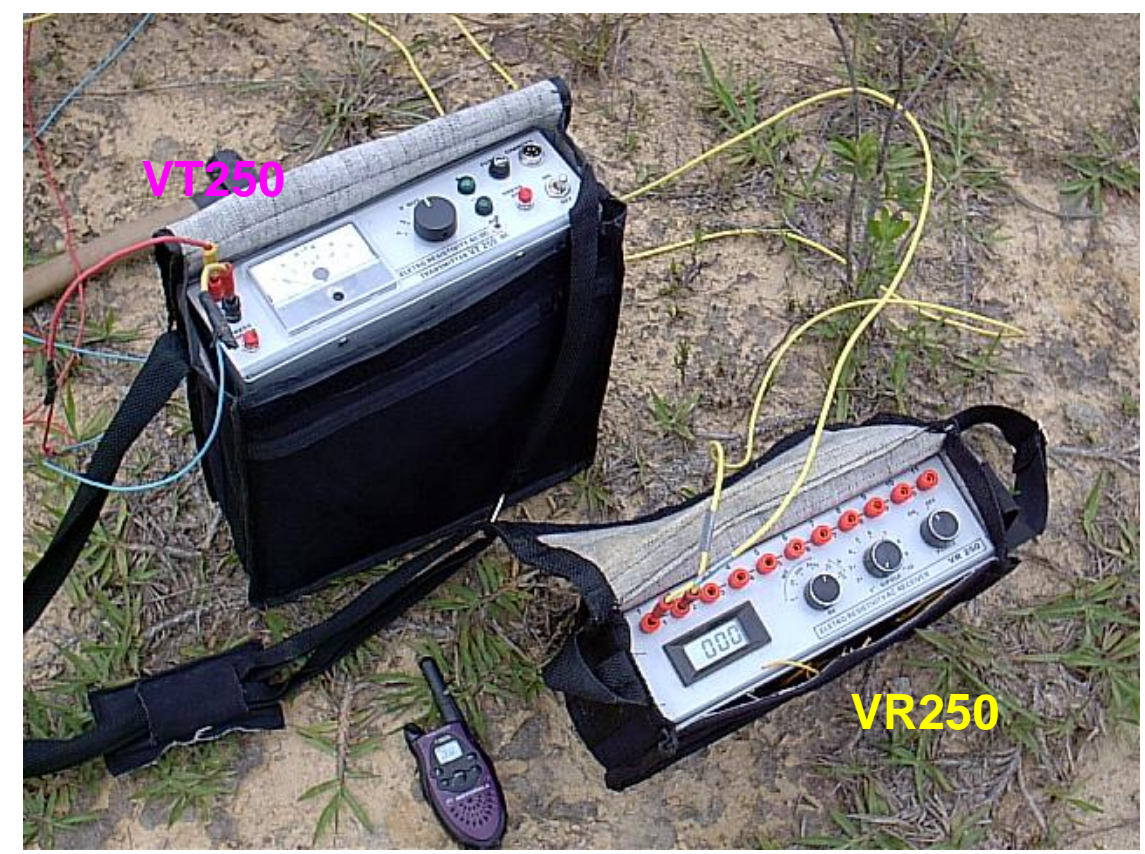

Figura 9. Transmissor VT250 e Receptor VR250. 


\section{Resultados e Discussão}

\subsection{Dados geofísicos}

Os métodos geofísicos permitem obter informações sobre a subsuperfície sem a necessidade de sondagens mecânicas ou escavações. A determinação da natureza das estruturas subsuperficiais é feita a partir de medidas de propriedades físicas do meio estudado.

A resistividade elétrica, ou sua inversa, a condutividade, exibe uma grande variação condicionada principalmente pelo conteúdo de umidade e pela salinidade. Quanto maior a umidade e conteúdo de material em solução na água subsuperficial, menos resistivo torna-se o solo (Nascimento 2003; Becegato et al. 2005a).

Devido a grande heterogeneidade do meio geológico, é natural que cada tipo litológico apresente uma resposta diferente em relação ao parâmetro físico da resistividade elétrica. De outra maneira, este parâmetro pode refletir diferentes formas de ocorrência de um mesmo material geológico, servindo para caracterizar seus estados, em termos de alteração, fraturamento, saturação, conteúdo mineral, etc.

Linha L1 (Figura 10) A resistividade aparente observada na pseudoseção variou de 58 a 932 Ohm.m, caracterizando um meio medianamente heterogêneo entre resistivos e condutivos. Qualitativamente observou-se a presença de núcleos resistivos predominando nos níveis mais profundos e no centro-leste da seção. A seção de resistividade real reflete uma unidade condutiva superficial e localizada desde o inicio até a estação 70. Esta unidade condutiva sobrepõe o embasamento resistivo composto por basaltos homogêneos. Também ocorre um pequeno núcleo condutivo isolado e localizado entre as estações 80 e 90 e na profundidade de 5 a 15 metros.

Linha L2 (Figura 11) esta linha apresentou limites resistivimétricos entre 127 e 1750 Ohm.m, o que reflete uma variação mais acentuada entre os tratos condutivos e resistivos. Basicamente os primeiros se concentram nos níveis mais rasos e predominantes no centroleste. A seção de resistividade real exibe uma unidade condutiva superficial localizada entre as estações 80 e110 metros e no embasamento nas profundidades maiores no centro da seção. No restante da seção predominam valores resistivos. 


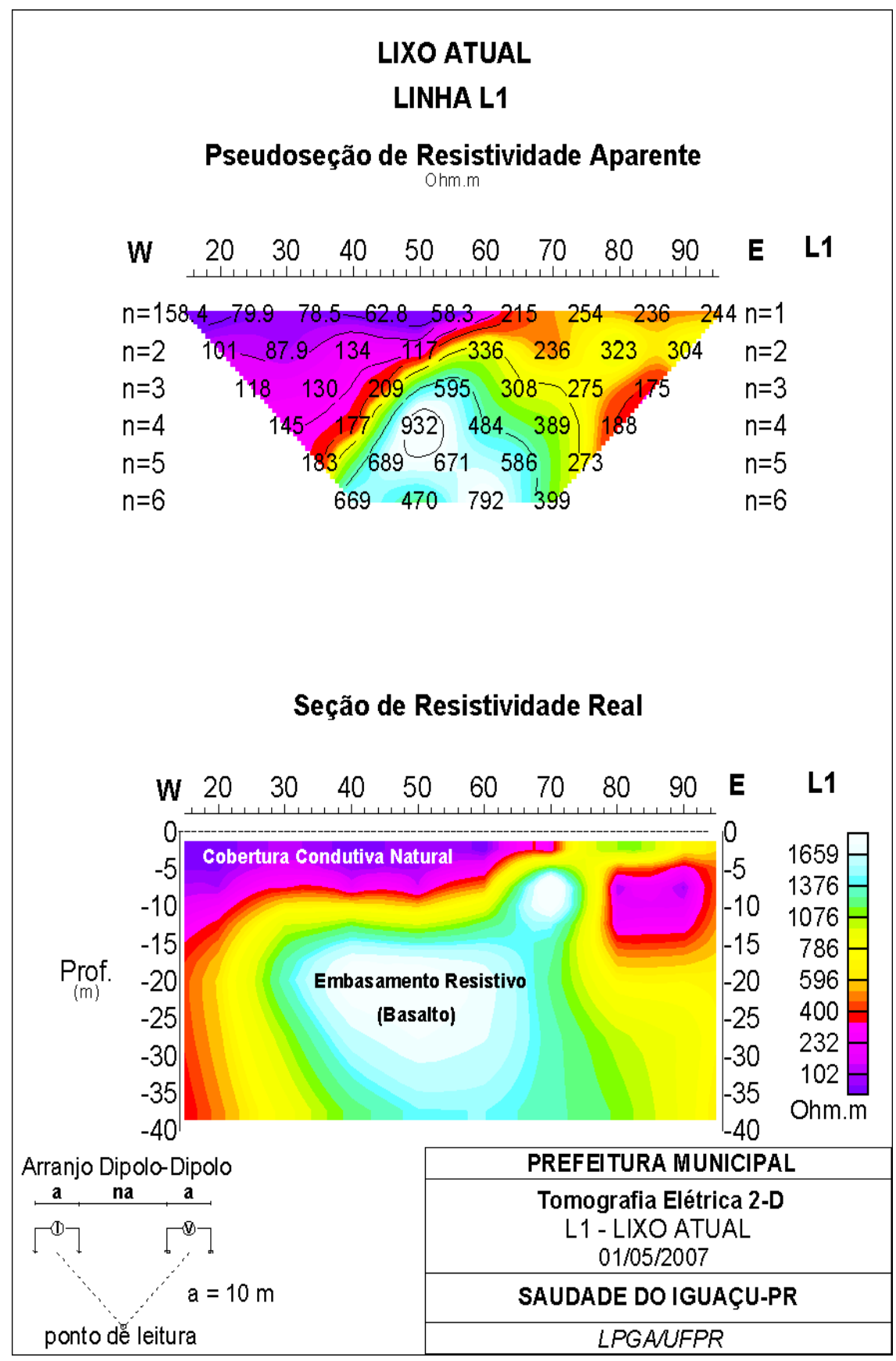

Figura 10 - Pseudoseção de resistividade aparente e seção de resistividade real da Linha L1 do depósito de lixo atual. 


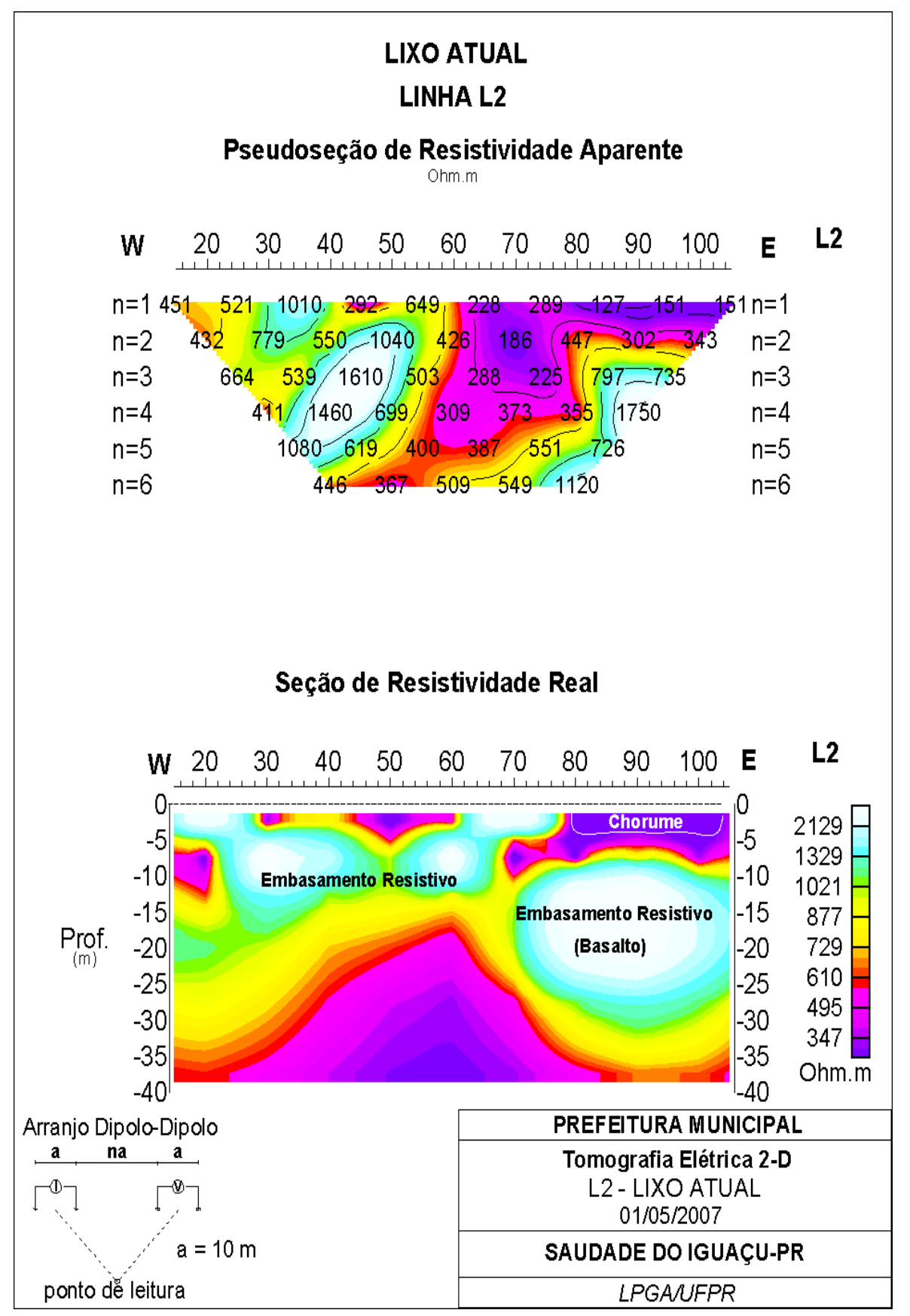

Figura 11 - Pseudoseção de resistividade aparente e seção de resistividade real da Linha L2 do depósito de lixo atual.

Linha L3 (figura 12) o comportamento geoelétrico da pseudoseção revela uma predominância de camadas resistivas nos estratos mais profundos, cujos valores oscilaram entre 157 e 661 Ohm.m. Na seção de resistividade real os pacotes resistivos também concentram-se na partes mais profundas. A camada condutiva mais relevante ocorre desde o início da seção até a estação 50, a qual é mais expressiva superficialmente. 


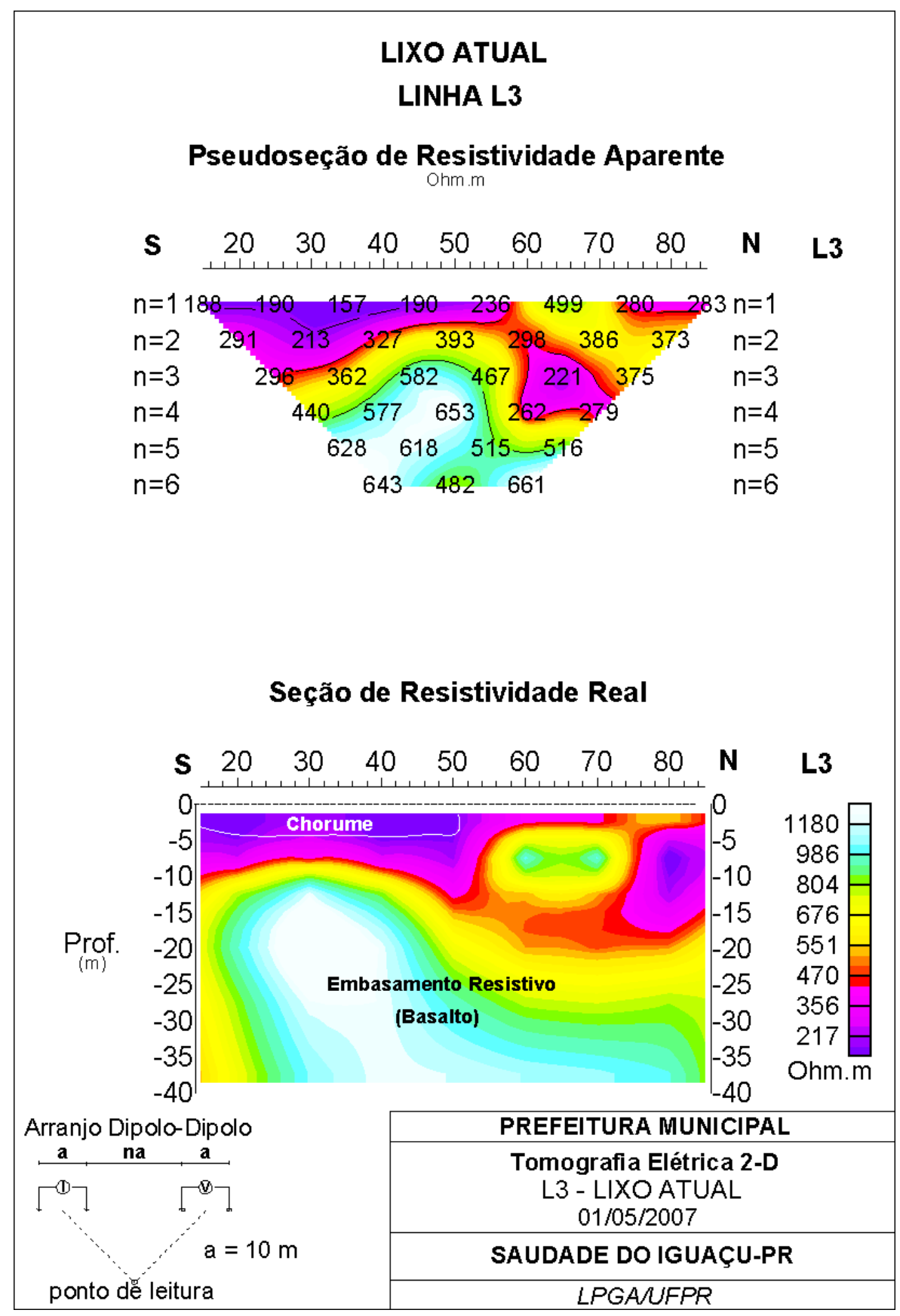

Figura 12 - Pseudoseção de resistividade aparente e seção de resistividade real da Linha L3 do depósito de lixo atual.

Finalmente na Linha L4 (figura 13) - A pseudoseção aparente revelou uma unidade condutiva (87 Ohm.m) nos níveis mais rasos e concentrados no centro-norte da linha, enquanto os resistivos (674 Ohm.m) se limitaram aos níveis mais profundos e no lado sul. Na seção de resistividade real o comportamento geoelétrico identificou uma camada condutiva superficial a partir da estação 45 metros e até a terminação setentrional do modelo, com extensão em profundidade até os 25 metros. Nos demais locais o ambiente é resistivo. 


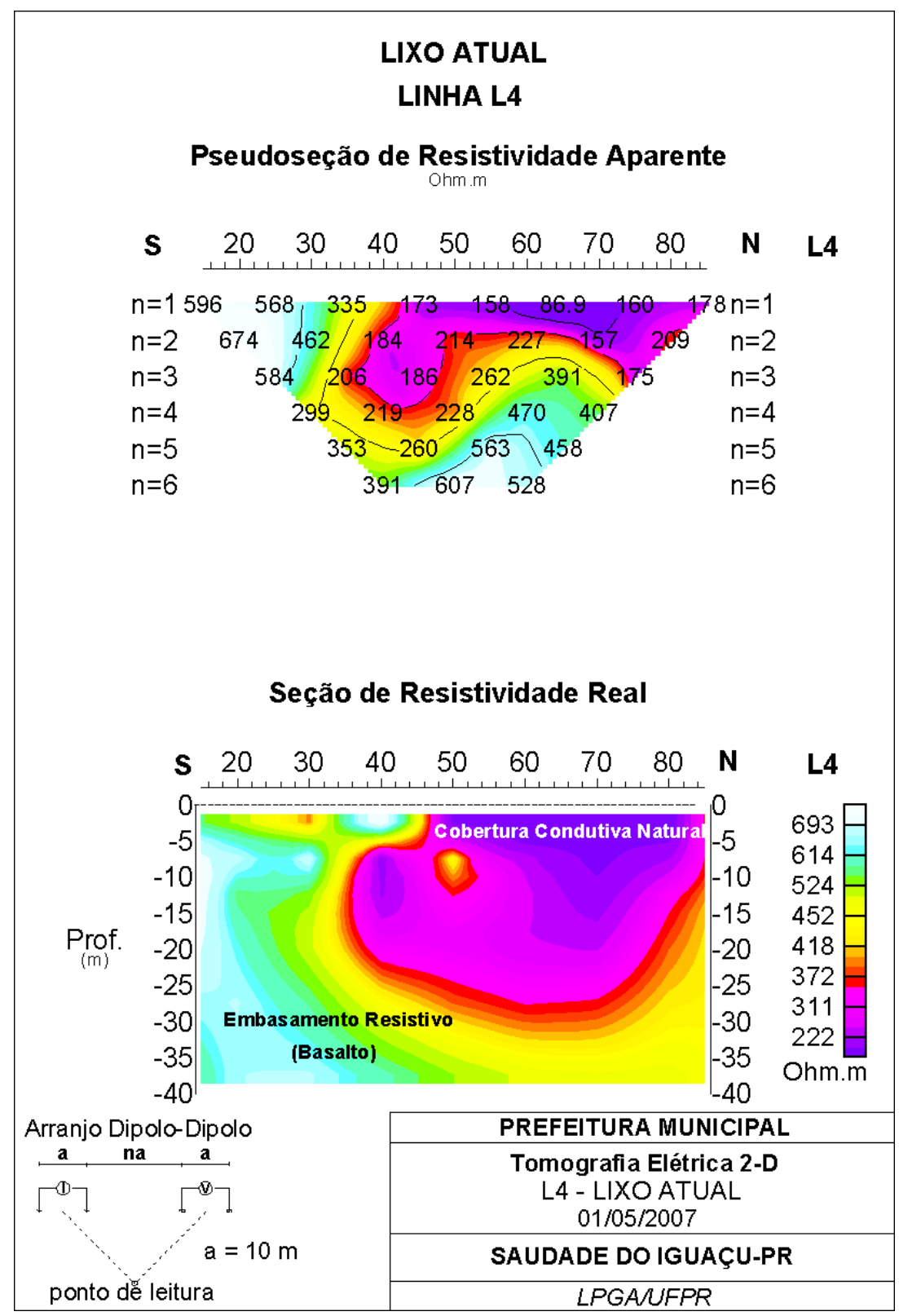

Figura 13 - Pseudoseção de resistividade aparente e seção de resistividade real da Linha L4 do depósito de lixo atual.

\section{4 - Conclusões}

As seções geofísicas realizadas no depósito de lixo atual demonstraram que o substrato pedo-litológico não está sendo muito afetado pela disposição do lixo aflorante, exceto nos locais interceptados pelo final da Linha L2 e início da L3 e de maneira muito superficial.

Os demais locais condutivos identificados no inicio da Linha L1 e final da Linha L4, provavelmente se correlacionam com uma cobertura natural de características geoelétricas derivadas de ambiente saturado ou de regolito fraturado. 


\section{5 - Referências}

BECEGATO, V.A. Aplicação de técnicas geofísicas e geoquímicas em duas glebas agrícolas no noroeste do estado do Paraná e suas relações com fertilizantes fosfatados. Curitiba, 2005. 198p. (Tese de Doutorado - Universidade Federal do Paraná).

BECEGATO, V.A. \& FERREIRA, J.F.F. Gamaespectrometria, resistividade elétrica e susceptibilidade magnética de solos agrícolas no noroeste do estado do Paraná. Revista Brasileira de Geofísica. vol. 23(4), p.371-405, 2005.

BRAGA, A.C.O. Métodos Geoelétricos Aplicados - Módulo Hidrogeologia, material didático. www.rc.unesp.br/ ou acobraga@ @rc.unesp.br. 2002

GALlAS, J.D.F., TAIOLI, F., SILVA, S.M.C.P., COELHO, O.G.W \& PAIM, P.S.G. Contaminação por chorume e sua detecção por resistividade. Revista Brasileira de Geofísica. vol. 23(1), p.51-59, 2005.

KOEFOED, O. Resistivity Souding Measurements. Elsevier, Amsterdan, 276p. 1979

LIMA, L.M.Q. Lixo - Tratamento e Biorremediação. $3^{\text {a }}$ edição. Editora Hemus. 265p. 2004.

MAACK, R. Geografia física do Estado do Paraná. 2. ed. Rio de Janeiro: José Olympio, $1981,442 \mathrm{p}$.

MARQUES, L.S. Rare elements. In: Piccirillo, E.M.; Melfi, A. J. The Mesozoic flood Volcanism of The Paraná Basin. São Paulo: Universidade de São Paulo, Instituto Astronômico e Geofísico, 1988. p.499-504.

NASCIMENTO, C.T.C. Resistividade elétrica e radiação gama natural no estudo de solos sob serrado nativo. Brasília, 2003. 115p. (Tese de Doutorado - Universidade de Brasília).

PARANÁ. MINERAIS DO PARANÁ S. A. - MINEROPAR. Atlas da geologia do Estado do Paraná. Curitiba, 2000.

PICCIRILO, E. M.; MELFI, A. J. Mesozoic Flood Volcanism of the Paraná Basin. São Paulo: Universidade de São Paulo, Instituto Astronômico e Geofísico, 1998. 600p.

TELFORD WM, GELDART LP \& SHERIFF RE. Applied geophysics. Second Edition. Cambridge, 1990. 770p. 